\title{
Commercialisation of AR1 in Australia
}

J.W. EVANS

Heritage Seeds, Australia johne@heritageseeds.com.au

\begin{abstract}
Perennial ryegrass containing a high level of standard (wild) endophyte is a significant component of the feed base for the grazing industries in the high rainfall and irrigated regions of Australia. The AR1 selected endophyte was first commercialised in Australia by Heritage Seeds in autumn 2002 into a market that had low awareness, and a limited understanding, of perennial ryegrass endophyte. The early uptake of AR1 was slow, mainly due to difficulties with delivering a very technical message with limited resources and justifying a significant price increase with no independent supporting data from Australia. Changing the marketing message to focus on the potential benefits from AR1, along with support from the developers of AR1 (AgResearch) and an overall increase in awareness of ryegrass endophyte, saw a dramatic increase in the uptake of AR1 varieties in 2005 and 2006. It is expected that this trend toward selected endophytes will continue into the future.
\end{abstract}

Keywords: perennial ryegrass, endophyte, AR1, commercialisation

\section{Introduction}

Perennial ryegrass is the mainstay of the high rainfall and irrigated pasture based animal production in south-eastern Australia. It is used extensively in regions with greater than 600 $\mathrm{mm}$ annual rainfall for dairy, beef and sheep meat production and varies from 50 year old naturalised pastures based on Victorian perennial ryegrass or Kangaroo Valley to the latest elite cultivars from Australian and New Zealand breeding programs. The majority of these perennial ryegrass pastures contain high levels of standard endophyte. This paper outlines the background, processes and challenges in the commercialisation of the AR1 selected endophyte in Australia by Heritage Seeds.

\section{Use of Perennial Ryegrass in Australia}

Perennial ryegrass use in Australia occurs over a wide range of environmental regions as diverse as the high rainfall, relatively short summer environs of southern Victoria and Northern Tasmania, the long dry summer beef and sheep production areas of central Tasmania, western and north-eastern Victoria and southeastern NSW, through to the flood irrigated dairy pastures under the hot summers of Northern Victoria and the NSW Riverina and the humidity of the Hunter Valley. Across these regions there are also a wide range of management practices from set stocked sheep or beef producers with low soil fertility through to high input intensively grazed dairy pastures.

These combinations of environment and management produce different expectations, and realities, for the performance of perennial ryegrasses. From 2-3 years persistence, with high productivity for irrigated dairy pastures in northern Victoria, the Riverina and the Hunter Valley, to 20 plus years persistence and lower productivity under extensive beef and sheep production in Western Victoria. This diversity presents challenges in introducing a new product to the market. Even if the target market is limited to dairy farmers, it must be evaluated under a wide range of environments and management practices to be sure it will perform. There may also be the need to develop different marketing messages to suit these diverse regions. This is all part of the significant market development costs for a new product.

\section{Endophyte Understanding Prior to AR1}

Before the release of AR1 in Australia, there was a low level of awareness of ryegrass endophyte among farmers and the industry in general. With the exception of a handful in the scientific community with a good understanding, most people in the pastoral industry who were aware of ryegrass endophyte had only a limited knowledge of its attributes and effects.

The limited understanding of ryegrass endophyte has at times resulted in misdiagnosis and misinformation, such as probable effects of endophyte being overlooked and issues that were probably not a direct effect of endophyte chemicals being wrongly attributed to it. Many of these misdiagnoses were driven by the potential for commercial benefit from endophyte related problems.

Among the few with a good understanding of ryegrass endophyte, there were conflicting views on its importance. The need for endophyte in perennial ryegrass in the Australian environment for the best plant persistence was fairly well established and there was some evidence that standard endophyte was limiting animal production.

The most recognised effect of ryegrass endophyte was sporadic outbreaks of ryegrass staggers, particularly in Western Victoria and Gippsland. While these outbreaks were a serious problem, the majority of farmers affected were beef or sheep producers who generally had low rates of pasture renovation and were price sensitive in seed purchase decisions. The dairy industry had higher rates of pasture renovation and was less price sensitive, but there was little recognition of any significant negative effects of ryegrass endophyte.

Nil or low endophyte varieties, varieties with a low percentage of seed containing live endophyte, had been evaluated in Australia and results showed there was a substantial yield and persistence loss compared to the wild endophyte equivalents. As a result the need for endophyte was generally accepted, although there were,

Figure 1 Heritage Seeds sales of AR1 varieties as a percentage of total perennial ryegrass sales since commercialisation of AR1 in 2002.

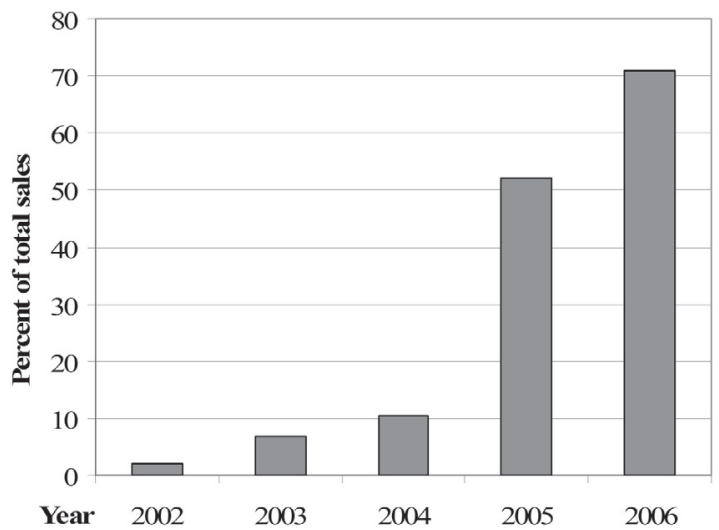


and still are, some companies marketing nil endophyte varieties with claims of persistence, that are generally unsubstantiated.

\section{AR1 Introduction and Marketing}

Heritage Seeds started marketing AR1 varieties in Australia in autumn 2002 with a combination of print advertising, technical fliers and farmer, reseller and advisor training sessions. These promotions included information on perennial ryegrass endophyte, endophyte alkaloids and their effects, as well as AR1 and its benefits. The need for added care in storage, handling and sowing of AR1 varieties was also covered.

\section{Main challenges}

The main challenge Heritage Seeds initially faced in marketing AR1 was to educate a market that had little knowledge of a very technical message. In addition was the need to overcome previous and ongoing misinformation, and justify a significant increase in seed price, with no independent agronomic or animal performance data from Australia. With limited resources available, these were difficult tasks.

There was no high profile research showing a clear benefit from AR1 over wild endophyte, or in fact that it would perform under Australian conditions. While Heritage Seeds had evaluated the performance of AR1 varieties against their wild endophyte counterparts, there was no independent data or data from the other seed companies to corroborate the results. In fact some of our competitors were actively trying to undermine the position of AR1.

The uptake of this new technology by the farmer and advisor community during this period was relatively slow. In hindsight, engaging some additional support from the developers of AR1 at this early stage may have improved the rate of uptake. Support from AgResearch (the developers of AR1) would have added a voice of authority and relative independence, and no doubt enhanced the acceptance of information by the market.

\section{Successes}

In 2004 our marketing messages changed from in-depth information, to focusing on the benefits of AR1. This was partly driven by increased understanding of endophyte in the industry but mostly by the need to simplify the message. This change was facilitated by publication of experimental results from New Zealand showing clear benefits in milk production from AR1 over wild endophyte. At this point AR1 became the main focus of our promotion of perennial ryegrass, with individual varieties being a secondary focus.

The change in marketing approach in 2004 was followed by a change to AR1 varieties being the default option, and standard endophyte being available on request, in 2005. And in 2006, with support from AgResearch and Grasslanz Technologies, three high profile regional seminars were held which included a presentation on AR1 and selected endophytes by Dr David Hume. The changes in marketing approach, combined with increasing awareness and understanding, saw a dramatic increase in uptake of AR1 as illustrated in Figure 1.

\section{Ongoing challenges}

Over the 5 years since the commercialisation of AR1 in Australia there has been a large increase in both the awareness and understanding of endophyte in the Australian market. There are still some opponents to AR1, attempting to sway the market against it, driven more by commercial interest than concerns about the performance or potential benefits of AR1 in Australia. As well as the opponents, there are conservative advisors and scientists taking a 'wait and see' approach. This is not helped by the continuing lack of independent Australian data on either the agronomic performance of AR1 or its effect on animal production.

While other seed companies are now bringing AR1 varieties to the Australian market, their approaches to date have been low key. There has also been a rapid increase in the number of selected endophytes being promoted with AR5, AR6 and NEA2 (and Max P in tall fescue) varieties on the market, and AR37 being mentioned. This has helped raise the awareness, but probably not the understanding, of endophytes in Australia.

\section{Future Outlook}

The ryegrass market in Australia will likely continue to move to selected endophyte varieties, especially in the dairy industry, more slowly in the beef and sheep markets. This move would be greatly aided by some independent agronomic and animal production data from trials conducted under Australian conditions.

Heritage Seeds is committed to the future development of this market in Australia and also to maintaining our position as technology leaders. In line with this commitment we will continue to promote and protect the position of AR1 in the market, and all new release perennial ryegrass varieties will contain a selected endophyte. 